\title{
End-group-functionalized poly( $N, N$-diethylacryl- amide) via free-radical chain transfer polymerization: Influence of sulfur oxidation and cyclodextrin on self-organization and cloud points in water
}

\author{
Sebastian Reinelt, Daniel Steinke and Helmut Ritter ${ }^{*}$
}

\section{Full Research Paper}

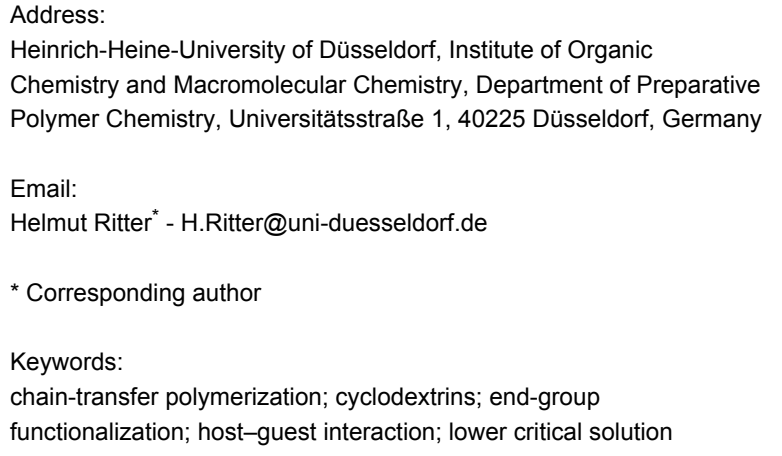

Heinrich-Heine-University of Düsseldorf, Institute of Organic Chemistry and Macromolecular Chemistry, Department of Preparative Polymer Chemistry, Universitätsstraße 1, 40225 Düsseldorf, Germany

Email:

Helmut Ritter ${ }^{*}$ - H.Ritter@uni-duesseldorf.de

* Corresponding author

Keywords:

chain-transfer polymerization; cyclodextrins; end-group

functionalization; host-guest interaction; lower critical solution

temperature (LCST); poly( $N, N$-diethylacrylamide)
Open Access

\author{
Beilstein J. Org. Chem. 2014, 10, 680-691. \\ doi:10.3762/bjoc. 10.61 \\ Received: 02 December 2013 \\ Accepted: 26 February 2014 \\ Published: 19 March 2014 \\ This article is part of the Thematic Series "Superstructures with \\ cyclodextrins: Chemistry and applications II". \\ Guest Editor: G. Wenz \\ (C) 2014 Reinelt et al; licensee Beilstein-Institut. \\ License and terms: see end of document.
}

\begin{abstract}
In this work we report the synthesis of thermo-, oxidation- and cyclodextrin- $(\mathrm{CD})$ responsive end-group-functionalized polymers, based on $N, N$-diethylacrylamide (DEAAm). In a classical free-radical chain transfer polymerization, using thiol-functionalized 4-alkylphenols, namely 3-(4-(1,1-dimethylethan-1-yl)phenoxy)propane-1-thiol and 3-(4-(2,4,4-trimethylpentan-2yl)phenoxy)propane-1-thiol, poly( $N, N$-diethylacrylamide) (PDEAAm) with well-defined hydrophobic end-groups is obtained. These end-group-functionalized polymers show different cloud point values, depending on the degree of polymerization and the presence of randomly methylated $\beta$-cyclodextrin (RAMEB-CD). Additionally, the influence of the oxidation of the incorporated thioether linkages on the cloud point is investigated. The resulting hydrophilic sulfoxides show higher cloud point values for the lower critical solution temperature (LCST). A high degree of functionalization is supported by ${ }^{1} \mathrm{H}$ NMR-, SEC-, FTIR- and MALDI-TOF measurements.
\end{abstract}

\section{Introduction}

Supramolecular chemistry was first defined by J. M. Lehn in the 1970 's as "chemistry of the intermolecular bond" $[1,2]$. However, its origin goes back to Fisher's "lock and key" model and also to Watson and Cricks description of the role of
H-bonds in DNA double helical structures. Both examples represent the importance of non-covalent interactions in living systems $[3,4]$. Since then, the field of self-assembly through molecular recognition has attracted much attention also in the 
design of smart materials. In this context, cyclodextrins (CD) are of interest as ring shaped host molecules, e.g., for the design of stimuli-responsive hydrogels [5] or of optical sensors [6] Certain stimuli-responsive materials are characterized by the presence of thioethers in the main chain. Tirelli et al. investigated the oxidation-responsive behavior of thioethers for biomedical applications [7-10]. The stimulus of these mostly poly(propylene sulfide) containing copolymers is based on the oxidation of thioethers to more hydrophilic sulfoxides or sulfones $[11,12]$. The specific sulfoxidation of a polymer bound end-group, which is in the focus of our present work, has not yet been investigated.

Polymeric materials exhibiting sensitivity to temperature are widely investigated [13]. Within this group of materials, thermosensitive water-soluble polymers, possessing a lower critical solution temperature (LCST), have attracted much attention in several studies within the last decades [13-17].

The nature of the end-group of a short chain polymer may have a certain impact on the temperature dependence solubility in aqueous media [18-24]. There are two prevalent approaches to introduce well-defined end-groups in the polymer backbone: (a) direct introduction by the use of suitable initiators respectively chain-transfer agents [23-25] or (b) indirect by polymer analogous modification of existing end-groups. For the post-modification highly efficient reactions are needed to ensure a high degree of functionalization. For this reason, often "click reactions" [26] such as esterifications [27], azide-alkyne [22], thiol-ene [28], thiol-isocyanate [29] and others are used. Thereby most studies have in common that synthesis of the polymer with thermo-responsive properties is preferably accomplished by either living anionic polymerization, or controlled radical polymerization [18,21,22,24,29-34]. Some publications make use of free-radical chain transfer polymerization and subsequent polymer post-modification $[25,27,35,36]$.
The scope of our investigation was the preparation of multiplestimuli-responsive PDEAAm polymers possessing hydrophobic end-groups suitable for host-guest interactions with $\beta$-cyclodextrin derivatives. Since 4-alkylphenyl moieties are good guests for $\beta$-cyclodextrin $[37,38]$, we were encouraged to use 4-tertbutylphenol as well as 4-tert-octylphenol and modify them with mercapto groups. By doing so, well-defined PDEAAm endgroup labeled polymers can be obtained by using classical freeradical chain transfer polymerization techniques. These polymers contain oxidation-sensitive thioether linkages. Up to now, to the best of our knowledge, the simultaneous influence of oxidation and cyclodextrin-sensitive end-groups on the solution properties of poly $(\mathrm{N}, \mathrm{N}$-diethylacrylamide $)$ has not been investigated.

\section{Results and Discussion}

Synthesis of thiol functionalized 4-alkylphenols. As depicted in Scheme 1, the synthesis of the thiol-functionalized phenol derivatives was accomplished in a three step synthesis. Etherification of the phenolic hydroxy groups of $\mathbf{1 a}$ and $\mathbf{1 b}$ with allyl bromide (2) and subsequent radical addition of ethanethioic $S$-acid (4) yielded the corresponding thioesters $S$-(3-(4-(1,1dimethylethan-1-yl)phenoxy)propyl) ethanthioate (5a) and $S$-(3(4-(2,4,4-trimethylpentan-2-yl)phenoxy)propyl) ethanthioate (5b). The thioester functions were hydrolyzed to obtain the thiols 3-(4-(1,1-dimethylethan-1-yl)phenoxy)propane-1-thiol (6a) and 3-(4-(2,4,4-trimethylpentan-2-yl)phenoxy)propane-1thiol (6b) in good yields after purification. The successful synthesis was furthermore confirmed by ${ }^{1} \mathrm{H}$ NMR, ${ }^{13} \mathrm{C} \mathrm{NMR}$ and FTIR spectroscopy as well as mass spectrometry (see Supporting Information File 1, Figures $\mathrm{S} 1$ to $\mathrm{S} 4$ for the ${ }^{1} \mathrm{H}$ and ${ }^{13} \mathrm{C}$ NMR data).

Synthesis of the end-group functionalized polymers. The thiol functionalized 4-alkylphenols (6a and $\mathbf{6 b}$ ) were used as chain transfer agents (CTA) for the free-radical polymerization

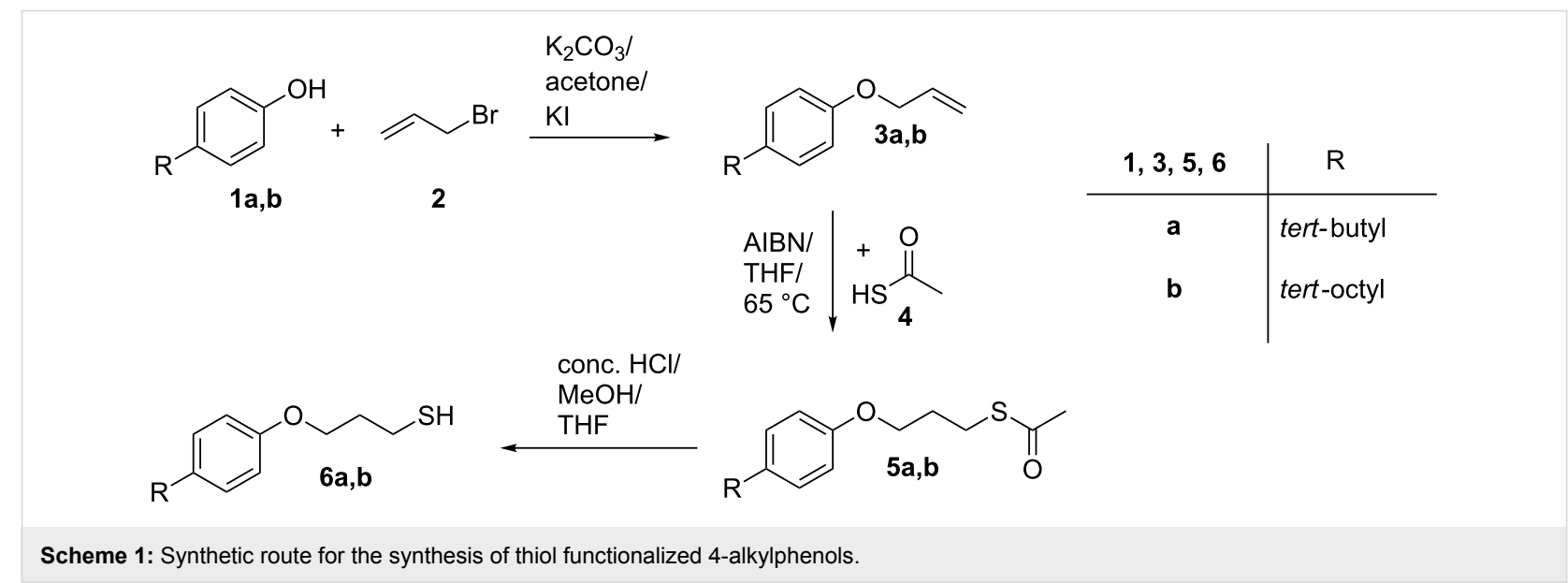


of $N, N$-diethylacrylamide (DEAAm) (7) (see Scheme 2). First the chain-transfer constant of $\mathbf{6 a}$ and $\mathbf{6 b}$ for the polymerization of DEAAm in $\mathrm{N}, \mathrm{N}$-dimethylformamide (DMF) at $70{ }^{\circ} \mathrm{C}$ was calculated from experimental results by using the Mayo method [39]. Chain-transfer constants of $\mathrm{C}_{\mathrm{Tr}, 6 \mathrm{a}}=0.84$ and $\mathrm{C}_{\mathrm{Tr}, 6 \mathrm{~b}}=0.87$ were found (see Supporting Information File 1, Figure S5), which are close to the ideal value of 1.0 where the concentration of the transfer agent relative to the monomer concentration remains constant [40].

For our investigation the molar ratio of [DEAAm] to [CTA] was varied from 20 to 1 up to 50 to 1 in order to investigate the influence of the chain length on the solubility in water. The molar ratio of [CTA] to [2,2'-azobis(2-methylpropionnitrile) (AIBN)] was kept thereby constant at a ratio of 20 to 1 . The final polymers (8a-d and $\mathbf{9 a}-\mathbf{d})$ were obtained as colorless solids after dialysis for 7 days. The analytical data of $\mathbf{8 a - d}$ and $\mathbf{9 a - d}$ are listed in Table 1.

Exemplarily, Figure 1 shows a section of the MALDI-TOF spectrum of polymer $\mathbf{8 b}$ confirming a high degree of 4-tertbutylphenol end-group functionalization. Just single series of peaks with a peak separation of 127.1 which corresponds to the mass of DEAAm plus the proposed end-group (224.1) and<smiles>[R]c1ccc(OCCC[SH2+])cc1</smiles>

Scheme 2: Synthetic route for the chain transfer polymerization of $N, N$-diethylacrylamide (7) with CTA $6 \mathbf{a}$ and $\mathbf{6 b}$ and subsequent oxidation of the resulting polymers to the corresponding polymers containing sulfoxides.

Table 1: Number average molecular weights $\left(\bar{M}_{\mathrm{n}}\right)$, dispersity $(\mathrm{D})$, glass transition temperatures $\left(T_{\mathrm{g}}\right)$ and cloud points of the end-group-functionalized polymers (8a-d and $\mathbf{9 a - d}$ ).

\begin{tabular}{lllllll} 
Polymer & CTA & $\begin{array}{l}\text { Ratio } \\
{[\mathrm{DEAAm}] /[\mathrm{CTA}]}\end{array}$ & $\begin{array}{l}\bar{M}_{\mathrm{n}} \\
{[\mathrm{kDa}]^{\mathrm{a}}}\end{array}$ & $\begin{array}{l}\bar{M}_{\mathrm{n}} \\
{[\mathrm{kDa}](\mathrm{D})^{\mathrm{b}}}\end{array}$ & $\begin{array}{c}T_{\mathrm{g}} \\
{\left[{ }^{\circ} \mathrm{C}\right]}\end{array}$ & $\begin{array}{l}\text { Cloud point } \\
{\left[{ }^{\circ} \mathrm{C}\right]^{\mathrm{C}}}\end{array}$ \\
\hline $\mathbf{8 a}$ & $\mathbf{6 a}$ & 20 & 2.5 & $3.3(4.0)$ & 49.1 & 15.1 \\
$\mathbf{8 b}$ & $\mathbf{6 a}$ & 30 & 4.8 & $5.6(3.0)$ & 62.3 & 21.2 \\
$\mathbf{8 c}$ & $\mathbf{6 a}$ & 40 & 6.1 & $5.7(3.2)$ & 65.9 & 24.3 \\
$\mathbf{8 d}$ & $\mathbf{6 a}$ & 50 & 7.8 & $7.2(2.8)$ & 75.3 & 25.8 \\
\hline $\mathbf{9 a}$ & $\mathbf{6 b}$ & 20 & 2.9 & $3.4(3.7)$ & 50.4 & 21.3 \\
$\mathbf{9 b}$ & $\mathbf{6 b}$ & 30 & 4.4 & $5.4(3.1)$ & 63.9 & 25.2 \\
$\mathbf{9 c}$ & $\mathbf{6 b}$ & 40 & 5.9 & $5.2(3.4)$ & 73.2 & 27.6 \\
$\mathbf{9 d}$ & $\mathbf{6 b}$ & 50 & 7.2 & $6.9(3.0)$ & 75.4 & 28.7 \\
\hline
\end{tabular}

aDetermined by ${ }^{1} \mathrm{H}$ NMR spectroscopy through end-group analysis; ${ }^{b}$ determined by size exclusion chromatography with DMF as eluent and a lower cut off of the column of $1.0 \mathrm{kDa}$; ' determined by turbidimetry measurements at a heating rate of $1 \mathrm{~K} / \mathrm{min}$. The concentration was $10 \mathrm{mg} / \mathrm{mL}$ in Millipore water. The cloud point values were derived from the heating curve. 


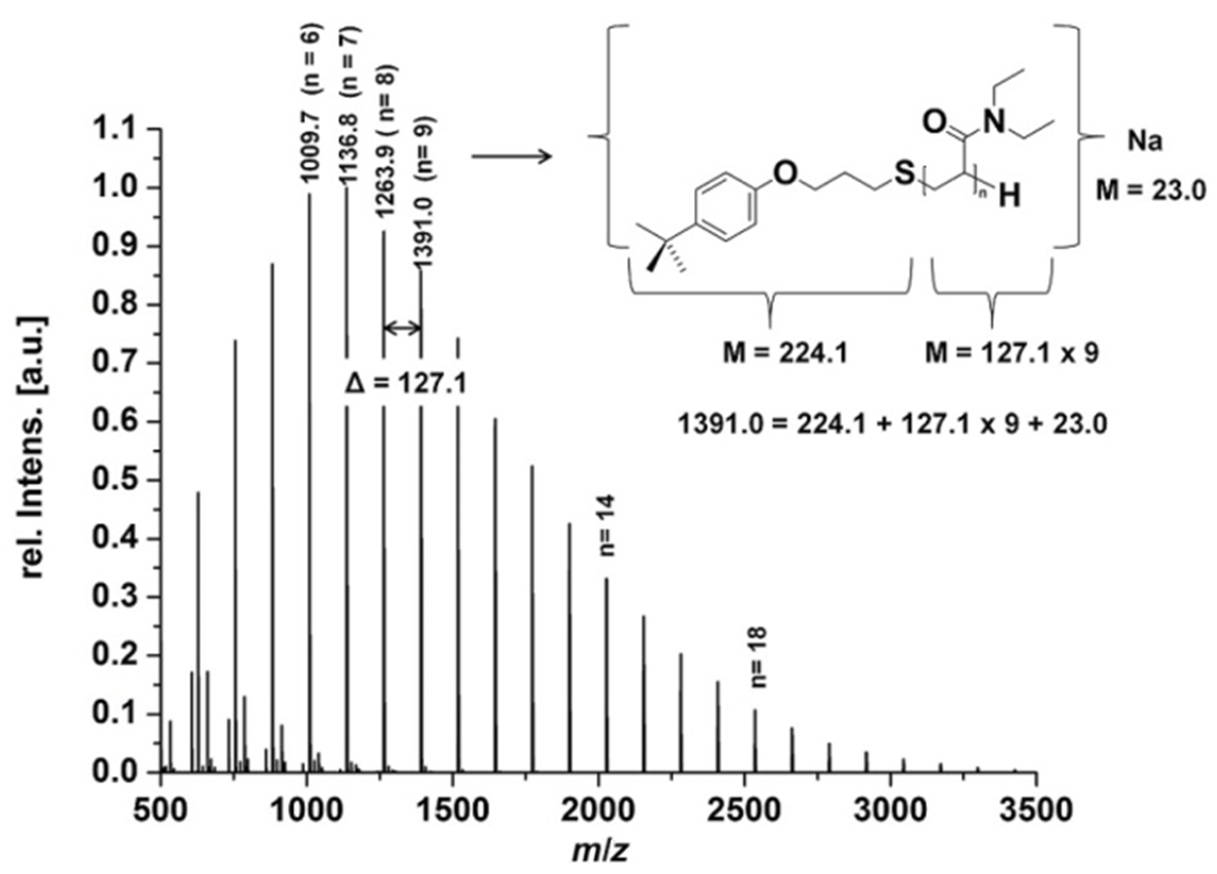

Figure 1: Section of the MALDI -TOF spectrum of polymer $\mathbf{8 b}$, indicating the high degree of end-group functionalization by the use of free-radical chain transfer polymerization.

sodium (23) can be found. Additionally, the $\bar{M}_{\mathrm{n}}$ values determined from SEC data were in agreement with the values calculated by end-group analysis based on ${ }^{1} \mathrm{H}$ NMR measurements (see Table 1). The NMR based $\bar{M}_{\mathrm{n}}$ values were obtained by comparing the integral of aromatic signals at $6.7-6.8 \mathrm{ppm}$ and 7.1-7.3 ppm with the signals of the backbone between

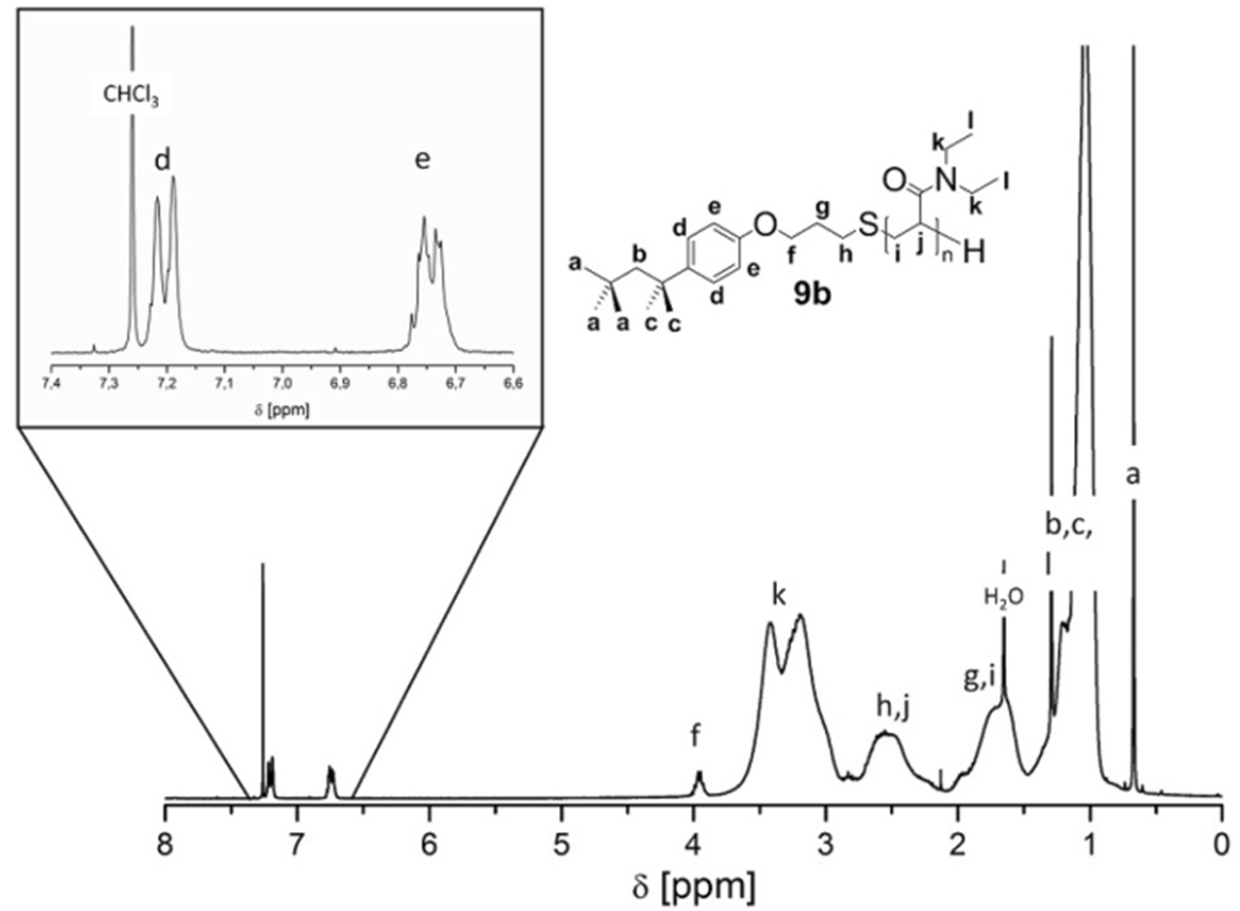

Figure 2: ${ }^{1} \mathrm{H}$ NMR spectrum of polymer $9 \mathrm{~b}$ in $\mathrm{CDCl}_{3}(300 \mathrm{MHz}, \mathrm{rt})$. 
2.0-3.9 ppm and 0.7-2.0 ppm, respectively (see Figure 2 for polymer 9b and Supporting Information File 1, Figure S6 for 8b).

Oxidation of the end-group-functionalized polymers. The selective oxidation of the thioether groups to the corresponding sulfoxides was accomplished by oxidation with hydrogen peroxide in analogy to literature [11].

As expected, the MALDI-TOF mass spectrum for $\mathbf{8 b O x}$ showed only one series of peaks, which was shifted by 16 Dalton in comparison to the origin series of peaks (see Figure 3). The FTIR spectrum showed a decrease of transmission at a wave length of $1024 \mathrm{~cm}^{-1}$ corresponding to the $\mathrm{S}=\mathrm{O}$ stretching vibration of the sulfoxide [11] and no shift of the $\mathrm{C}=\mathrm{O}$ vibration at $1625 \mathrm{~cm}^{-1}$. Additionally, the ${ }^{1} \mathrm{H}$ NMR spec- trum clearly indicated an upfield shift of the $\mathrm{OCH}_{2}$-group supporting also a successful oxidation. Thus the analytical data reveals no indication for further oxidation of the polymer chain or additional oxidized structures, e.g. of the methine groups in the main chain.

\section{Impact of the degree of polymerization and structure of the} end-group on the cloud point values. Aqueous solutions of poly $(N, N$-diethylacrylamide) (PDEAAm) exhibtit a coil to globule transition at the lower critical solution temperature (LCST) of approximately $33{ }^{\circ} \mathrm{C}$ in water for low molecular weight polymers as stated in previous studies $[41,42]$. In the present study, the cloud points of PDEAAm were measured on $1 \mathrm{wt} \%$ aqueous solution in water. A concentration of $1 \mathrm{wt} \%$ seemed to be a reasonable concentration since Idziak et al. [42] showed that a variation of the polymer concentration of
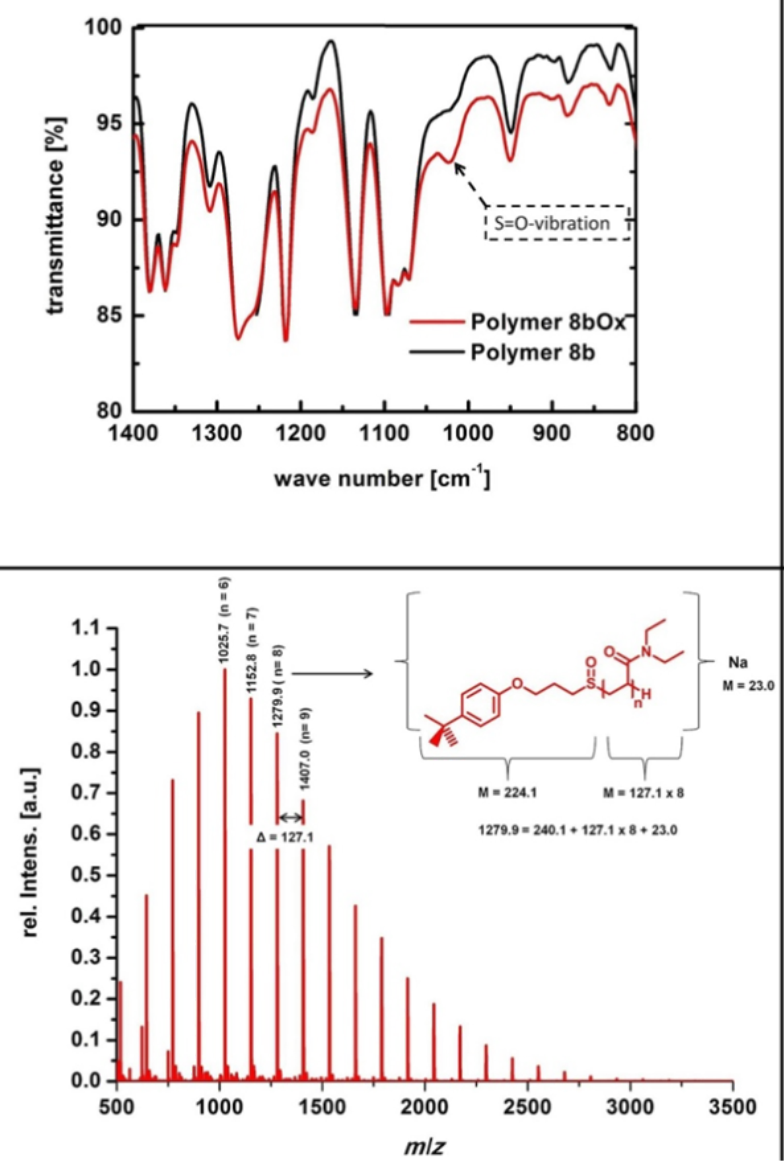
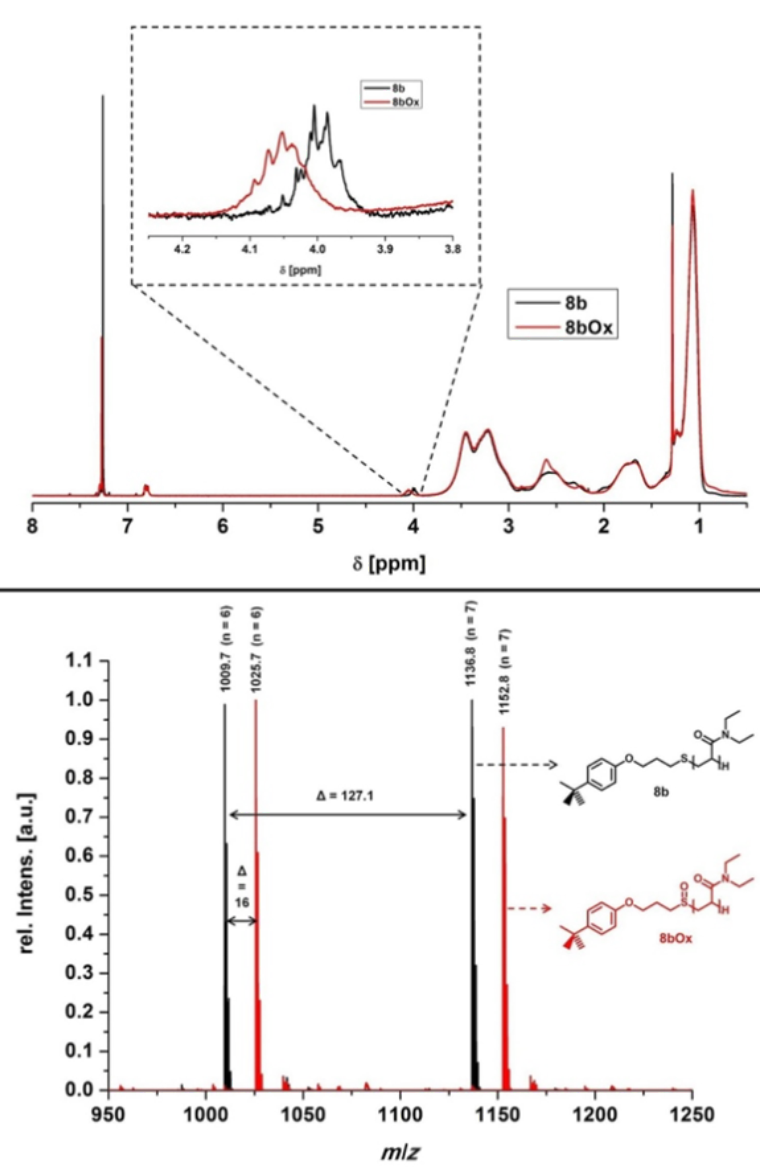

Figure 3: Top left: Section of the FTIR-spectrum of polymer $\mathbf{8 b}$ (black line) in comparison to $\mathbf{8 b O x}$ (red line); top right: ${ }^{1} \mathrm{H}$ NMR spectrum of polymer $\mathbf{8 b}$ (black line) and polymer $\mathbf{8 b O x}$ (red line) in $\mathrm{CDCl}_{3}(300 \mathrm{MHz}$, rt); bottom left: Section of the MALDI-TOF spectrum of polymer $\mathbf{8 b O x}$, supporting the high efficiency of the oxidation of the thioether linkage to the corresponding sulfoxides; bottom right: Comparison of the MALDI-TOF spectrum of polymer $\mathbf{8 b}$ (black line) with polymer $\mathbf{8 b O x}$ (red line). 
PDEAAm (obtained in a free-radical polymerization with AIBN as initiator) in the range of $0.5 \mathrm{wt} \%$ up to $20 \mathrm{wt} \%$ does not considerably affect the LCST.

All obtained polymers $(\mathbf{8 a}-\mathbf{d}, \mathbf{9 a}-\mathbf{d})$ were completely soluble in cold water below their LCST. Since the molecular weights of the presented polymers $(\mathbf{8 a}-\mathbf{d}, \mathbf{9 a}-\mathbf{d})$ were relatively low, the hydrophobic end-groups shifted the cloud point significantly to lower temperatures in comparison to the cloud point of unmodified PDEAAm. Accordingly, the impact of the hydrophobic end-group on the cloud point of the polymer increased with decreasing molecular weight and thus showing an inverse dependency (Figure 4 and Table 2). This is in agreement with the findings of previous studies. As stated by Chung et al. the dehydration of the polymer chain during the phase transition is initiated at the chain ends, where the mobility is highest [36]. For poly( $N$-isopropylacrylamide) (PNIPAM) previous studies demonstrated a broadened phase transition for polydisperse and low molecular weight samples $[18,32,43]$. Although the polymers $(\mathbf{8 a}-\mathbf{d}, \mathbf{9 a}-\mathbf{d})$ investigated in the present study were prepared via a free-radical instead of a living polymerization technique and had a relative low molecular weight, the optical transmission diagrams indicate a relatively sharp transition in a temperature range of $1{ }^{\circ} \mathrm{C}$ up to $2{ }^{\circ} \mathrm{C}$ as well as a good reversibility upon cooling (see Supporting Information File 1, Figures S7 and S8).

As it can be seen in Table 2 and Figure 4 the hydrophobic character caused by the chain-end was considerable for both types of end-groups. For instance, the cloud point of $\mathbf{8 d}$ $\left(\bar{M}_{\mathrm{n}}=7.8 \mathrm{kDa}\right)$ dropped from $25.8{ }^{\circ} \mathrm{C}$ to $15.1{ }^{\circ} \mathrm{C}$ for $8 \mathrm{a}$

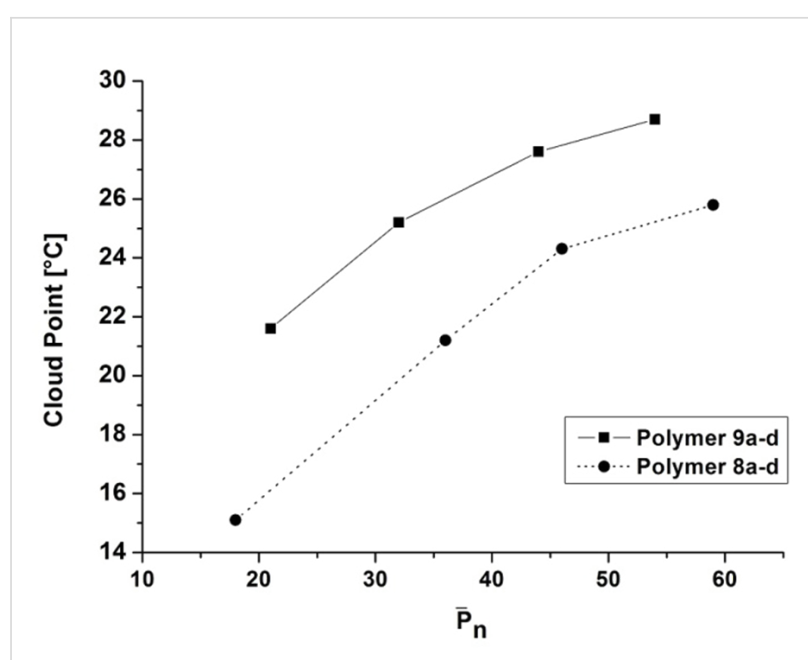

Figure 4: Dependency of the cloud point values on the degree of polymerization (calculated by end-group analysis based on ${ }^{1} \mathrm{H}$ NMR measurements).

$\left(\bar{M}_{\mathrm{n}}=2.5 \mathrm{kDa}\right)$ as the molecular weight decreased by $5.3 \mathrm{kDa}$. In contrast, with regard to cloud points of the 4-tert-octylphenol end-group functionalized polymers $(\mathbf{9 a}-\mathbf{d})$ only a drop from $28.7^{\circ} \mathrm{C}\left(\mathbf{9 d}, \bar{M}_{\mathrm{n}}=7.2 \mathrm{kDa}\right)$ to $21.3{ }^{\circ} \mathrm{C}\left(\mathbf{9 a}, \bar{M}_{\mathrm{n}}=2.9 \mathrm{kDa}\right)$ was found whereas the molecular weight decreased by $4.3 \mathrm{kDa}$. Our findings regarding the cloud point depression of thermoresponsive polymers containing hydrophobic end-groups with decreasing molecular weight $[20,24,30,44]$ or the effect of an increasing hydrophobic environment in amphiphilic conetworks [45] are in accordance with previous studies. Theoretically a stronger remarkable effect on the cloud point of the polymers bearing a 4-tert-octylphenol end-group compared to the

\begin{tabular}{|c|c|c|c|c|c|c|}
\hline \multirow{2}{*}{ Polymer } & \multirow{2}{*}{$\begin{array}{l}\bar{M}_{\mathrm{n}}\left(P_{\mathrm{n}}\right) \\
{[\mathrm{kDa}]^{\mathrm{a}}}\end{array}$} & \multicolumn{2}{|c|}{$\begin{array}{l}\text { Cloud Point } \\
{\left[{ }^{\circ} \mathrm{C}\right]^{b}}\end{array}$} & \multicolumn{3}{|c|}{$\begin{array}{l}\text { Cloud Point after addition of RAMEB-CD } \\
\qquad\left[{ }^{\circ} \mathrm{C}\right]^{b}\end{array}$} \\
\hline & & Before oxidation & After oxidation $^{c}$ & $\begin{array}{l}1 \text { equiv } \\
\text { RAMEB-CD }\end{array}$ & $\begin{array}{l}2 \text { equiv } \\
\text { RAMEB-CD }\end{array}$ & $\begin{array}{l}4 \text { equiv } \\
\text { RAMEB-CD }\end{array}$ \\
\hline $8 a$ & 2.5 (18) & 15.1 & 21.0 & 27.9 & 34.2 & 34.2 \\
\hline $8 b$ & $4.8(36)$ & 21.2 & 28.8 & 24.5 & 33.6 & 33.8 \\
\hline $8 c$ & $6.1(46)$ & 24.3 & 30.0 & 26.2 & 33.4 & 33.4 \\
\hline $8 d$ & $7.8(59)$ & 25.8 & 30.7 & 27.0 & 33.2 & 33.5 \\
\hline $9 a$ & $2.9(21)$ & 21.3 & 24.3 & $-^{e}$ & 21.1 & 33.7 \\
\hline $9 b$ & $4.4(32)$ & 25.2 & 27.4 & $-^{e}$ & 20.7 & 33.3 \\
\hline $9 c$ & $5.9(44)$ & 27.6 & 28.2 & 19.6 & 22.4 & 33.2 \\
\hline $9 d$ & $7.2(54)$ & 28.7 & 28.8 & 26.3 & 27.2 & 33.3 \\
\hline
\end{tabular}

aDetermined by ${ }^{1} \mathrm{H}$ NMR spectroscopy through end-group analysis; ${ }^{b}$ determined by turbidimetry measurements at a heating rate of $1 \mathrm{~K} / \mathrm{min}$. The

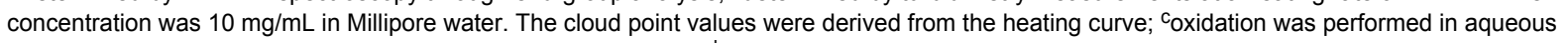
hydrogen peroxide solution as stated in the experimental section; ${ }^{d}$ the stoichiometry was calculated on the basis of the data obtained from end-group analysis based on ${ }^{1} \mathrm{H}$ NMR measurements; ethe polymer is insoluble in water, no optical clear solution down to $5^{\circ} \mathrm{C}$. 
4-tert-butylphenol end-group could be expected. Consequently hydrophobic interactions must play an important role for this effect. Regarding Figure 4 and Table 2 the hydrophobic interactions seem to be stronger for the 4-tert-octylphenol-modified polymers and thus leading to higher cloud points since aggregation leads to a suppression of the hydrophobicity of a polymer $[25,35,36]$.

Impact of oxidation of the thioether-linkages on the solution properties. Since the polymers bear thioether groups, the influence of their oxidation to sulfoxides on the cloud point was investigated. The more hydrophilic polar sulfoxide group in comparison to the thioether group should lead to an increase of solubility in water. Thus higher cloud point values for all polymers were found (see Table 2). The cloud point shifts are shown in Figure 5 for polymer $\mathbf{8}$ as well as $\mathbf{9}$. The illustration indicates that the strength of response to oxidation of the aqueous solutions of polymers $\mathbf{8}$ and $\mathbf{9}$ is a function of the degree of polymerization. Thus the oxidation showed a more remarkable cloud point shift of the short chain polymers. Furthermore, it turned out, that the cloud points of the 4-tert-butylphenol endgroup functionalized polymers $(\mathbf{8 a}-\mathbf{d})$ were tunable to a larger extent via oxidation compared to the polymers bearing the 4-tert-octylphenol group. For instance polymer $\mathbf{8 b}$ showed a threefold higher cloud point shift $\left(7.6^{\circ} \mathrm{C}\right)$ than the corresponding 4-tert-octylphenol-bearing polymer $9 \mathbf{b}\left(2.2^{\circ} \mathrm{C}\right)$. As an example, the cloud point curve of polymer $\mathbf{8 b}$ before and after oxidation is illustrated in Figure 6.

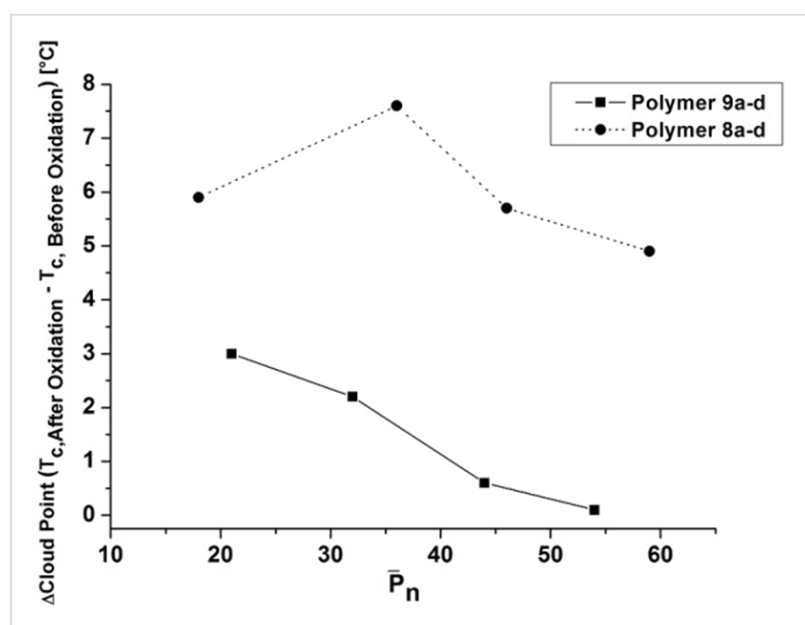

Figure 5: Shifts of the cloud points after the oxidation of the polymers (8a-d, 9a-d) to its corresponding sulfoxides (8aOx-8dOx, $9 \mathrm{aOx}-9 \mathrm{dOx})$ as a function of degree of polymerization.

Complexation of the polymer end-groups with randomlymethylated- $\beta$-cyclodextrin (RAMEB-CD) - Impact on the cloud points. In addition the solution properties of polymers $\mathbf{8 a}-\mathbf{d}$ and $9 \mathbf{a}-\mathbf{d}$ as a function of temperature were also evaluated in the presence of different amounts of RAMEB-CD. In general, the 4-tert-butylphenyl as well as the 4-tert-octylphenyl end-group are able to build host-guest inclusion complexes with the RAMEB-CD cavity $[38,46]$. This interaction was verified by 2D NOESY NMR spectroscopy clearly showing correlation signals between the protons of the RAMEB-CD cavity and the

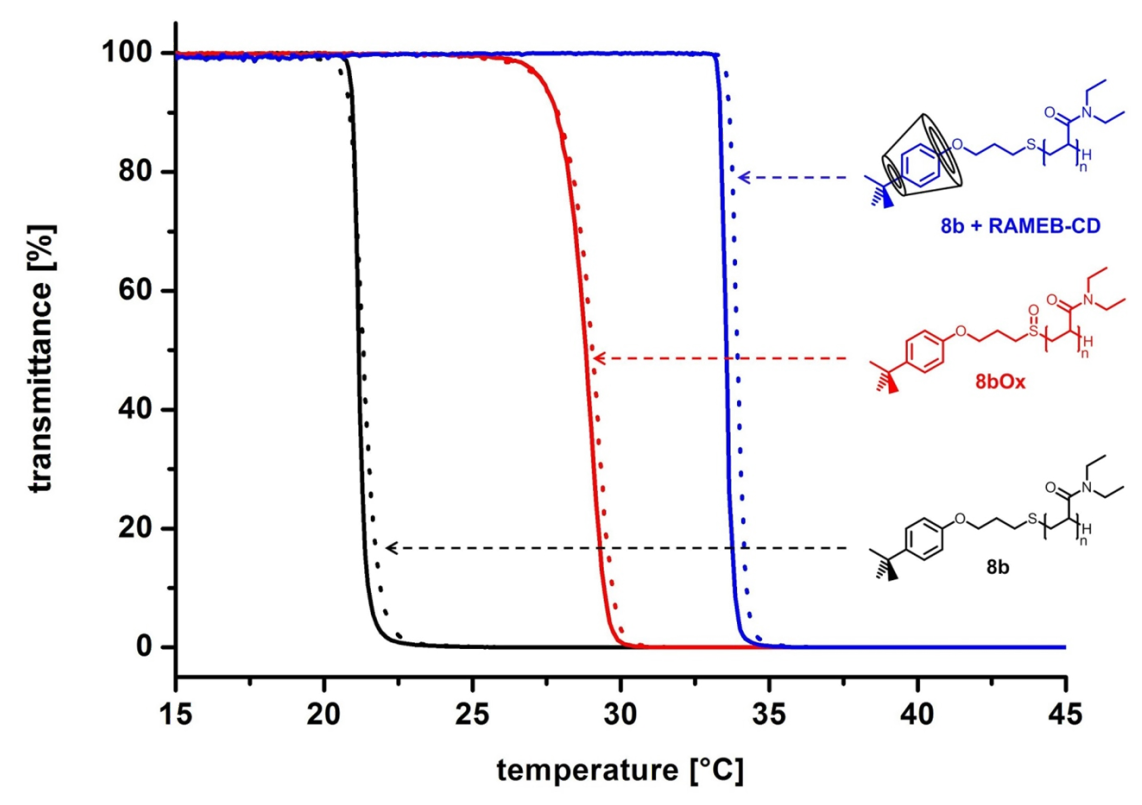

Figure 6: Turbidimetry measurements of polymer $\mathbf{8 b}$ (straight black line - heating curve; dotted black line - cooling curve), 8 b0x (straight red line heating curve; dotted red line - cooling curve) and the complex of $\mathbf{8 b}$ and RAMEB-CD (2 equiv) (straight blue line - heating curve; dotted blue line cooling curve) in aqueous solution at a concentration of $10 \mathrm{mg} / \mathrm{mL}$. 
aromatic protons as well as the aliphatic protons in case of the 4-tert-octyl end-group. Exemplarily, in Figure 7 the 2D NOESY spectrum of polymer $\mathbf{8 b}$ in the presence of RAMEB-CD is shown.

The formation of host-guest complexes of the polymer bound end-group with the RAMEB-CD cavity should reduce the hydrophobic character of the end-group and thus increase the cloud points of the polymers to a value close to the value of pure PDEAAm as already shown by our group [24,47]. Taking a fourfold excess of RAMEB-CD in relation to the polymer end-group this assumption was fulfilled for all polymers $(\mathbf{8 a}-\mathbf{d}$ and $9 \mathbf{a}-\mathbf{d})$. The values of the cloud point were increased after complexation up to the range of $33.2{ }^{\circ} \mathrm{C}$ and $34.2{ }^{\circ} \mathrm{C}$, respectively (Table 2). However the addition of a twofold excess of RAMEB-CD to 8a-d increased the cloud points also to values above $33{ }^{\circ} \mathrm{C}$. Exemplarily, the shift of the cloud point curve of polymer $\mathbf{8 b}$ after addition of two equivalents RAMEB-CD is illustrated in Figure 6. The addition of only an equimolar amount of RAMEB-CD caused an increase of the cloud points of 8a-d up to values between $24.5^{\circ} \mathrm{C}(\mathbf{8 b})$ and $27.9^{\circ} \mathrm{C}(\mathbf{8 a})$ (Table 2). Due to the fact that the host-guest interactions are equilibria and the sterical accessibility of the polymer bound end-group is difficult, a slight excess of RAMEB-CD is necessary for the complete covering of each 4-tert-butylphenol endgroup. These findings are in accordance with the literature $[24,44]$.

The addition of equimolar amounts of RAMEB-CD to solutions of polymers 9a-d containing 4-tert-octylphenol endgroups led to an unexpected decrease of the cloud point. This effect was most remarkable for the low molecular weight polymers 9a and 9b. For instance, a polymer 9a was fully insoluble in water in the presence of one equivalent RAMEB-CD even at temperatures down to $5{ }^{\circ} \mathrm{C}$. In case of polymer $9 \mathrm{c}$ the cloud point dropped from 27.6 to $19.6{ }^{\circ} \mathrm{C}$. Increasing the amount of RAMEB-CD led to an increase of the cloud points again.

Dynamic light scattering measurements: Influence of RAMEB-CD on self-organization behavior. Dynamic light scattering (DLS) measurements were conducted in order to understand the surprising phenomena that the cloud point of 4-tert-octylphenol end-group bearing polymers first decreased by adding small amounts of RAMEB-CD (one equivalent) to the aqueous polymer solution and subsequent increased again by rising the amount of RAMEB-CD up to four equivalents.

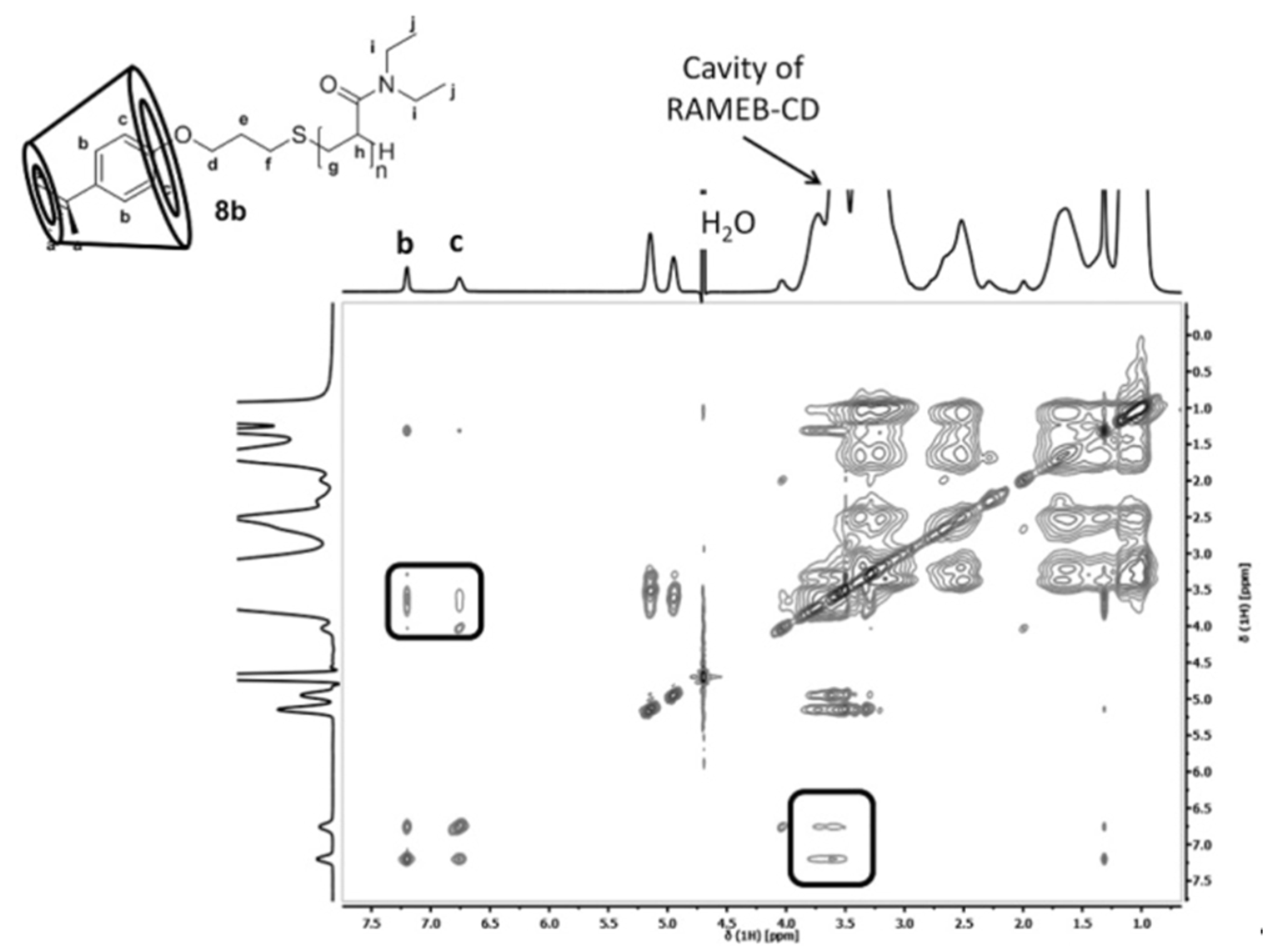

Figure 7: 2D NMR NOESY spectrum of polymer $8 \mathbf{b}$ with two equivalents RAMEB-CD in $\mathrm{D}_{2} \mathrm{O}(600 \mathrm{MHz}, \mathrm{rt})$. 
The number averaged hydrodynamic diameters $\left(d_{h}\right)$ of the polymers $\mathbf{8 a}-\mathbf{d}$ and $\mathbf{9 a}-\mathbf{d}$ in aqueous solution (concentration: $10 \mathrm{mg} / \mathrm{mL}$; temperature: $10^{\circ} \mathrm{C}$ ) were determined to $4.6 \mathrm{~nm}$ up to $6.8 \mathrm{~nm}$. The addition of one equivalent RAMEB-CD to the aqueous polymer solutions of $\mathbf{8 a}-\mathbf{d}$ and $\mathbf{9 c}-\mathbf{d}$ led to a decrease of the number averaged hydrodynamic diameter (see Table 3). Exemplarily Figure 8 shows the hydrodynamic diameter of aqueous solutions of polymer 9c, RAMEB-CD and polymer 9c in the presence of one equivalent RAMEB-CD.

Table 3: Number averaged hydrodynamic diameters of the polymers and the supramolecular complexes with RAMEB-CD in water at $10^{\circ} \mathrm{C}$.

\begin{tabular}{lcc} 
Polymer & \multicolumn{2}{c}{ Hydrodynamic diameter [nm] } \\
\cline { 2 - 3 } & $10 \mathrm{mg} / \mathrm{mL}$ & $\begin{array}{c}10 \mathrm{mg} / \mathrm{mL}+1 \text { equiv } \\
\text { RAMEB-CD }\end{array}$ \\
\hline 8a & & $2.4 \pm 0.8$ \\
8b & $6.3 \pm 1.6$ & $3.6 \pm 1.2$ \\
8c & $5.2 \pm 1.5$ & $3.4 \pm 1.2$ \\
8d & $5.4 \pm 1.5$ & $3.4 \pm 1.2$ \\
9a & $4.6 \pm 1.5$ & Insoluble \\
9b & $6.8 \pm 1.8$ & Insoluble \\
9c & $6.5 \pm 1.7$ & $2.9 \pm 1.0$ \\
9d & $6.5 \pm 1.8$ & $3.1 \pm 1.1$ \\
\hline
\end{tabular}

aAt a temperature of $10^{\circ} \mathrm{C}$ the solution was not optical clear, the sample is already aggregating.
These results indicated that the 4-tert-alkylphenol end-groups tend to aggregate strongly leading to the formation of intermolecular core-shell micellar-like structures as stated in Figure 8. However, it should be mentioned that especially after the addition of RAMEB-CD the intensity-weighted distributions showed also the formation of larger aggregates, but since the scattering intensity is dependent on the sixth power of the radius of the particle the percentage of these particles is exaggerated [48].

The formation of thermo-responsive micelles of end-group functionalized respectively block copolymers in aqueous solution have been investigated in previous studies $[35,48,49]$. Studies on hydrophobically PNIPAM have also demonstrated the formation of core-shell structures exhibiting a corona of PNIPAM chains $[25,35,36]$. The formation of micellar-like structures lead to an isolation of the hydrophobic end-groups from water and thus to a dramatically supression of the hydrophobicity of the polymer. Due to the interaction of the polymeric end-group with RAMEB-CD the formation of these core-shell structures is inhibited. The 4-tert-octylphenol endgroup has a stronger hydrophobic character compared to the 4-tert-butylphenol group. Furthermore, it is well know that RAMEB-CD is able to build 2:1 complexes with 4-tertoctylphenol derivatives [46]. Thus it seems likely that one equivalent RAMEB-CD is not sufficient to depress the hydrophobic character of the 4-tert-octylphenol end-group

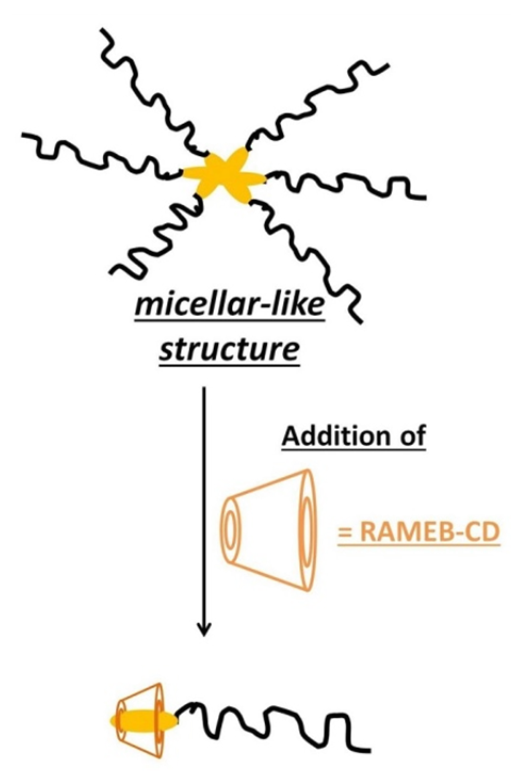

unimer

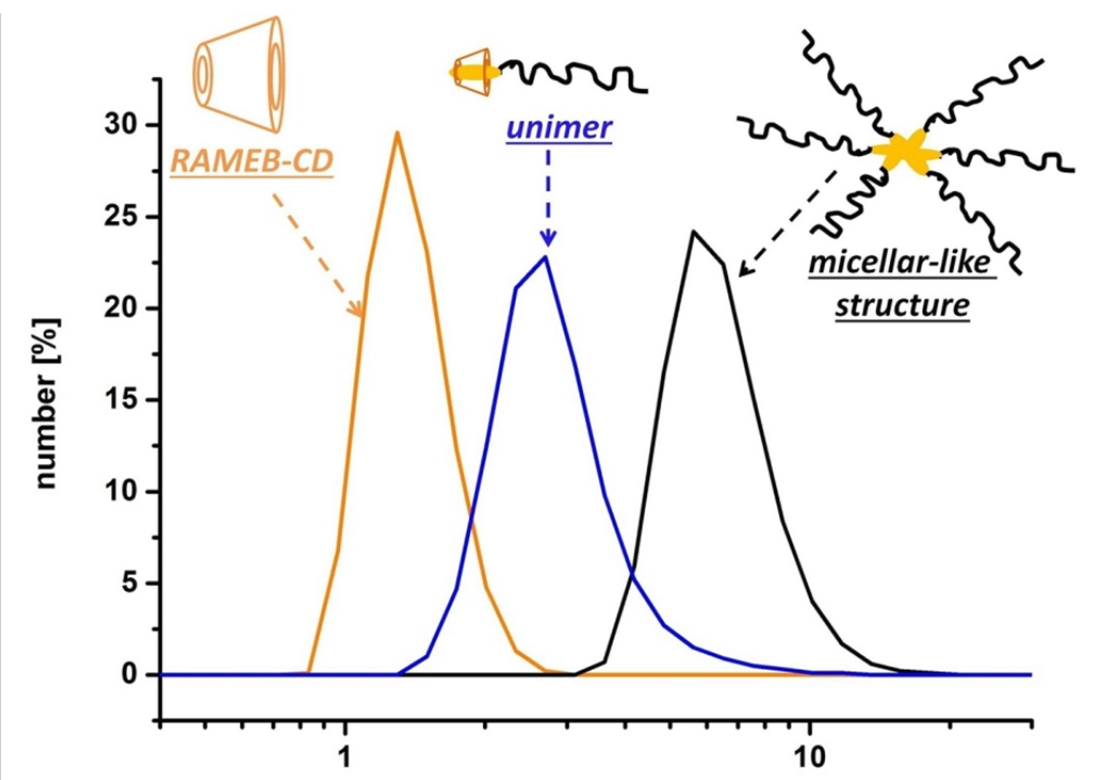

hydrodynamic diameter [nm]

Figure 8: Left: Schematic illustration of the micellar-like structures and reversibility by addition of RAMEB-CD; Right: DLS measurements size distributions for RAMEB-CD (orange line), 9c (black line) and 9c plus 1 equiv RAMEB-CD (blue line). 
completely, so that the micellar-like structures of $\mathbf{9 a}-\mathbf{d}$ in aqueous solution are more hydrophilic than the supramolecular complexes of 9a-d with one equivalent RAMEB-CD. Consequently, as described above, a decrease of the cloud points of aqueous solutions of polymers 9a-d were observed when adding only one equivalent RAMEB-CD. In case of the 4-tertbutylphenol modified polymers $\mathbf{8 a}-\mathbf{d}$ the supramolecular complexes are more hydrophilic than the micellar-like struc- tures hence an increase of the cloud points were observed by addition of one equivalent RAMEB-CD. This phenomenon is illustrated in Figure 9.

\section{Conclusion}

In summary, we have evidenced the synthesis and characterization of $\omega$-(4-alyklphenyl)-functionalized PDEAAm via freeradical chain transfer polymerization in $N, N$-dimethylfor-
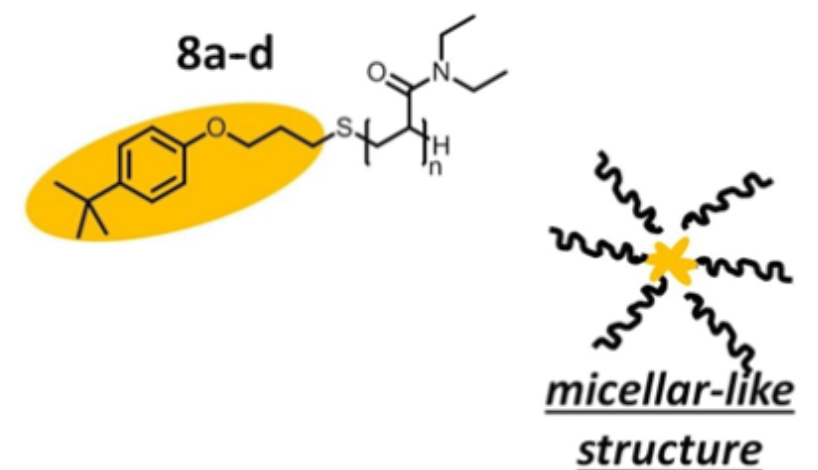

$8 \mathrm{a}-\mathrm{d}+1$ equiv RAMEB-CP

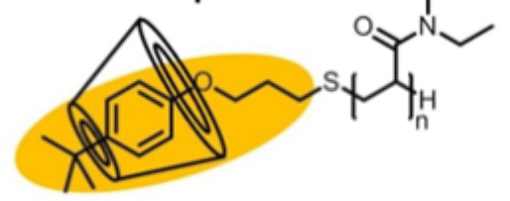

L

1

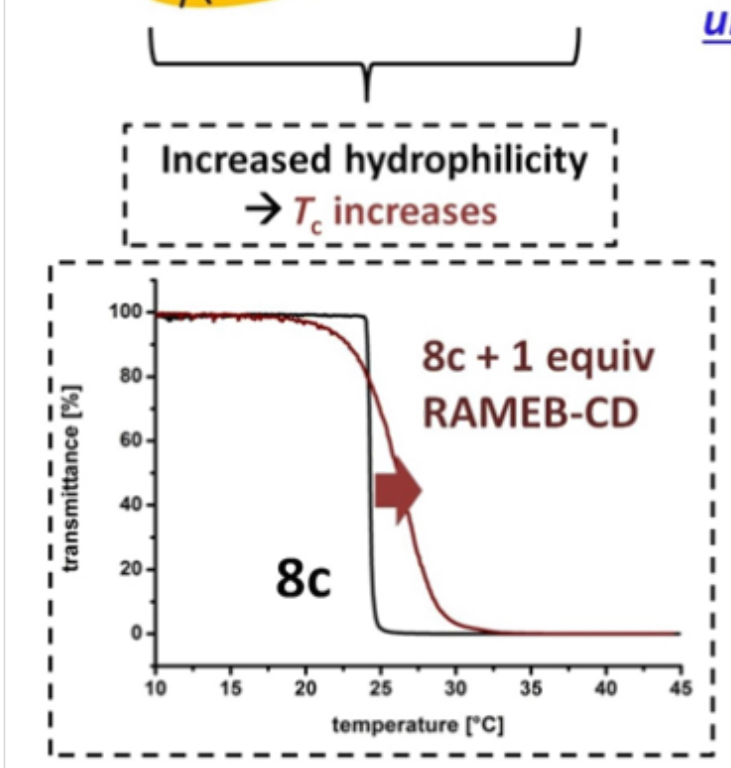

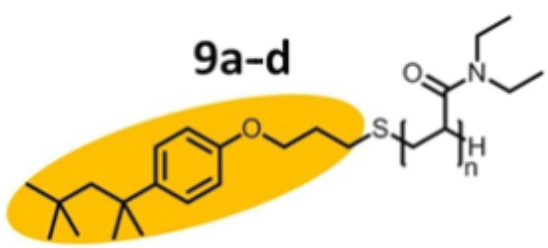

$x \times$
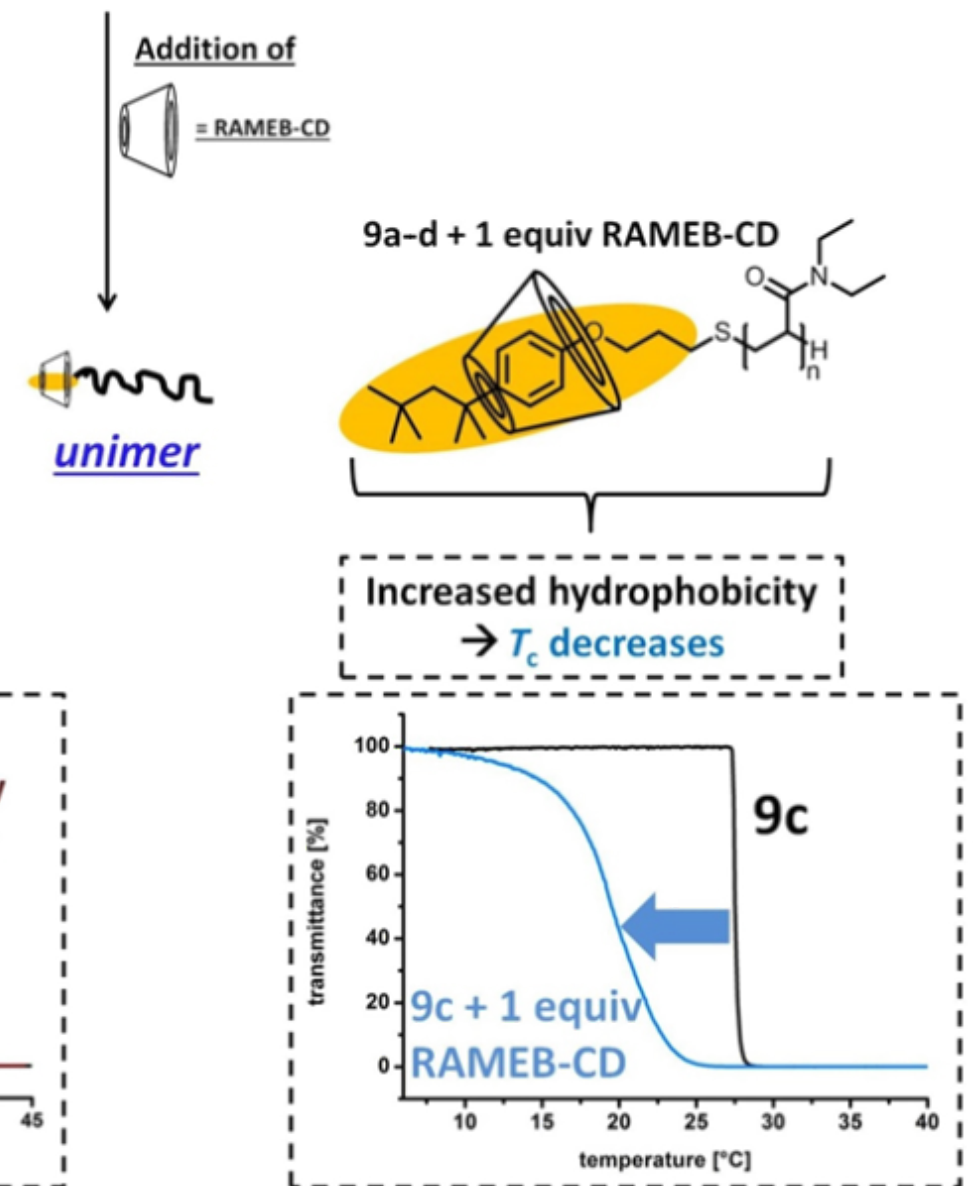

Figure 9: Schematic illustration of the micellar-like structures, its deformation upon addition of one equivalent RAMEB-CD and the influence on the cloud point values determined by turbitidy measurements on aqueous solutions (concentration: $10 \mathrm{mg} / \mathrm{mL}$ ). 
mamide as solvent. By changing the feed ratio of [CTA] to [DEAAm] the solution properties were tunable. A linear decrease of the cloud point with a decreasing degree of polymerization was observed. Aqueous polymer solutions showed multiple-stimuli-responsive behavior.

The cloud points of the aqueous polymer solutions were tunable by two different stimuli. The incorporated thioether linkages were addressable by oxidation. The corresponding more hydrophilic sulfoxides showed an increase of the cloud point values up to almost $8^{\circ} \mathrm{C}$ depending on the end-group and the molecular weight of the polymer. Thus we were able to show for the first time the influence of sulfur oxidation of polymer bound end-groups on the solution properties in water. Simultaneously the cloud points were tunable by the addition of RAMEB-CD. The cloud points of all polymers (8a-d, 9a-d) could shift to a value of $33-34{ }^{\circ} \mathrm{C}$ in case of RAMEB-CD in excess.

\section{Supporting Information}

A full experimental section can be found in the Supporting Information. Description of the materials, characterization methods and syntheses of the obtained compounds; spectroscopic data $\left({ }^{1} \mathrm{H},{ }^{13} \mathrm{C}\right.$ and $2 \mathrm{D}$ NMR $)$; curves of the turbidity measurements, Mayo-Plot for the determination of the chain transfer constant.

\section{Supporting Information File 1}

Title Experimental part.

[http://www.beilstein-journals.org/bjoc/content/ supplementary/1860-5397-10-61-S1.pdf]

\section{References}

1. Lehn, J. M. Pure Appl. Chem. 1978, 50, 871-892. doi:10.1351/pac197850090871

2. Lehn, J.-M. Angew. Chem., Int. Ed. Engl. 1990, 29, 1304-1319. doi:10.1002/anie.199013041

3. Fischer, E. Ber. Dtsch. Chem. Ges. 1894, 27, 2985-2993. doi:10.1002/cber.18940270364

4. Watson, J. D.; Crick, F. H. C. Nature 1953, 171, 737-738. doi:10.1038/171737a0

5. Yamaguchi, H.; Kobayashi, Y.; Kobayashi, R.; Takashima, Y.; Hashidzume, A.; Harada, A. Nat. Commun. 2012, 3, No. 603. doi:10.1038/ncomms1617

6. Fleischmann, C.; Ritter, H. Macromol. Rapid Commun. 2013, 34, 1085-1089. doi:10.1002/marc.201300292

7. Hu, P.; Tirelli, N. Bioconjugate Chem. 2012, 23, 438-449. doi:10.1021/bc200449k

8. Napoli, A.; Valentini, M.; Tirelli, N.; Müller, M.; Hubbell, J. A. Nat. Mater. 2004, 3, 183-189. doi:10.1038/nmat1081
9. Lallana, E.; Tirelli, N. Macromol. Chem. Phys. 2013, 214, 143-158. doi:10.1002/macp.201200502

10. Li, M.-H.; Keller, P. Soft Matter 2009, 5, 927-937. doi:10.1039/b815725a

11. Carampin, P.; Lallana, E.; Laliturai, J.; Carroccio, S. C.; Puglisi, C.; Tirelli, N. Macromol. Chem. Phys. 2012, 213, 2052-2061. doi:10.1002/macp.201200264

12. Napoli, A.; Boerakker, M. J.; Tirelli, N.; Nolte, R. J. M.; Sommerdijk, N. A. J. M.; Hubbell, J. A. Langmuir 2004, 20, 3487-3491. doi:10.1021/la0357054

13. Schmaljohann, D. Adv. Drug Delivery Rev. 2006, 58, 1655-1670. doi:10.1016/j.addr.2006.09.020

14. Liu, H. Y.; Zhu, X. X. Polymer 1999, 40, 6985-6990. doi:10.1016/S0032-3861(98)00858-1

15. Dimitrov, I.; Trzebicka, B.; Müller, A. H. E.; Dworak, A.; Tsvetanov, C. B. Prog. Polym. Sci. 2007, 32, 1275-1343. doi:10.1016/j.progpolymsci.2007.07.001

16. Roy, D.; Brooks, W. L. A.; Sumerlin, B. S. Chem. Soc. Rev. 2013, 42, 7214-7243. doi:10.1039/c3cs35499g

17. de las Heras Alarcón, C.; Pennadam, S.; Alexander, C. Chem. Soc. Rev. 2005, 34, 276-285. doi:10.1039/b406727d

18. Plummer, R.; Hill, D. J. T.; Whittaker, A. K. Macromolecules 2006, 39, 8379-8388. doi:10.1021/ma0614545

19. Pietsch, C.; Schubert, U. S.; Hoogenboom, R. Chem. Commun. 2011, 47, 8750-8765. doi:10.1039/c1cc11940k

20. Jochum, F. D.; zur Borg, L.; Roth, P. J.; Theato, P. Macromolecules 2009, 42, 7854-7862. doi:10.1021/ma901295f

21. Akiyama, H.; Tamaoki, N. Macromolecules 2007, 40, 5129-5132. doi:10.1021/ma070628v

22. Narumi, A.; Fuchise, K.; Kakuchi, R.; Toda, A.; Satoh, T.; Kawaguchi, S.; Sugiyama, K.; Hirao, A.; Kakuchi, T. Macromol. Rapid Commun. 2008, 29, 1126-1133. doi:10.1002/marc.200800055

23. Kujawa, P.; Segui, F.; Shaban, S.; Diab, C.; Okada, Y.; Tanaka, F.; Winnik, F. M. Macromolecules 2006, 39, 341-348. doi: $10.1021 / \mathrm{ma} 051876 z$

24. Schmidt, B. V. K. J.; Hetzer, M.; Ritter, H.; Barner-Kowollik, C. Macromol. Rapid Commun. 2013, 34, 1306-1311. doi:10.1002/marc.201300478

25. Winnik, F. M.; Davidson, A. R.; Hamer, G. K.; Kitano, H. Macromolecules 1992, 25, 1876-1880. doi:10.1021/ma00033a006

26. Kolb, H. C.; Finn, M. G.; Sharpless, K. B. Angew. Chem., Int. Ed. 2001, 40, 2004-2021. doi:10.1002/1521-3773(20010601)40:11<2004::AID-ANIE2004>3.3.CO ;2-X

27. Maatz, G.; Maciollek, A.; Ritter, H. Beilstein J. Org. Chem. 2012, 8, 1929-1935. doi:10.3762/bjoc.8.224

28. Yu, B.; Chan, J. W.; Hoyle, C. E.; Lowe, A. B. J. Polym. Sci., Part A: Polym. Chem. 2009, 47, 3544-3557. doi:10.1002/pola.23436

29. Li, H.; Yu, B.; Matsushima, H.; Hoyle, C. E.; Lowe, A. B. Macromolecules 2009, 42, 6537-6542. doi:10.1021/ma9010878

30. Xia, Y.; Burke, N. A. D.; Stöver, H. D. H. Macromolecules 2006, 39, 2275-2283. doi:10.1021/ma0519617

31. Matyjaszewski, K.; Xia, J. Chem. Rev. 2001, 101, 2921-2990. doi:10.1021/cr940534g

32. Xia, Y.; Yin, X.; Burke, N. A. D.; Stöver, H. D. H. Macromolecules 2005, 38, 5937-5943. doi:10.1021/ma050261z

33. Hales, M.; Barner-Kowollik, C.; Davis, T. P.; Stenzel, M. H. Langmuir 2004, 20, 10809-10817. doi:10.1021/la0484016 
34. Freitag, R.; Baltes, T.; Eggert, M. J. Polym. Sci., Part A: Polym. Chem. 1994, 32, 3019-3030. doi:10.1002/pola.1994.080321603

35. Chung, J. E.; Yokoyama, M.; Aoyagi, T.; Sakurai, Y.; Okano, T. J. Controlled Release 1998, 53, 119-130. doi:10.1016/S0168-3659(97)00244-7

36. Chung, J. E.; Yokoyama, M.; Suzuki, K.; Aoyagi, T.; Sakurai, Y.; Okano, T. Colloids Surf., B 1997, 9, 37-48. doi:10.1016/S0927-7765(97)00015-5

37. Rekharsky, M. V.; Inoue, Y. Chem. Rev. 1998, 98, 1875-1918. doi:10.1021/cr970015o

38. Müller, B.-K.; Ritter, H. J. Inclusion Phenom. Macrocyclic Chem. 2012, 72, 157-164. doi:10.1007/s10847-011-9955-0

39. Mayo, F. R. J. Am. Chem. Soc. 1943, 65, 2324-2329. doi:10.1021/ja01252a021

40. Matyjaszewski, K.; Davis, T. P., Eds. Handbook of radical polymerization; John Wiley and Sons: Hoboken, 2002. doi:10.1002/0471220450

41. Lessard, D. G.; Ousalem, M.; Zhu, X. X.; Eisenberg, A.; Carreau, P. J. J. Polym. Sci., Part B: Polym. Phys. 2003, 41, 1627-1637. doi:10.1002/polb.10517

42. Idziak, I.; Avoce, D.; Lessard, D.; Gravel, D.; Zhu, X. X. Macromolecules 1999, 32, 1260-1263. doi:10.1021/ma981171f

43. Schild, H. G.; Tirrell, D. A. J. Phys. Chem. 1990, 94, 4352-4356. doi:10.1021/j100373a088

44. Duan, Q.; Miura, Y.; Narumi, A.; Shen, X.; Sato, S.-I.; Satoh, T.; Kakuchi, T. J. Polym. Sci., Part A: Polym. Chem. 2006, 44, 1117-1124. doi:10.1002/pola.21208

45. Kali, G.; Vavra, S.; László, K.; Iván, B. I. Macromolecules 2013, 46, 5337-5344. doi:10.1021/ma400535r

46. Kemnitz, M.; Ritter, H. Beilstein J. Org. Chem. 2012, 8, 2176-2183. doi:10.3762/bjoc.8.245

47. Ritter, H.; Sadowski, O.; Tepper, E. Angew. Chem., Int. Ed. 2003, 42, 3171-3173. doi:10.1002/anie.200250814

48. André, X.; Zhang, M.; Müller, A. H. E. Macromol. Rapid Commun. 2005, 26, 558-563. doi:10.1002/marc. 200400510

49. Yan, J.; Ji, W.; Chen, E.; Li, Z.; Liang, D. Macromolecules 2008, 41 , 4908-4913. doi:10.1021/ma7026726

\section{License and Terms}

This is an Open Access article under the terms of the Creative Commons Attribution License (http://creativecommons.org/licenses/by/2.0), which permits unrestricted use, distribution, and reproduction in any medium, provided the original work is properly cited.

The license is subject to the Beilstein Journal of Organic Chemistry terms and conditions: (http://www.beilstein-journals.org/bjoc)

The definitive version of this article is the electronic one which can be found at: doi:10.3762/bjoc. 10.61 